\title{
Giant pulmonary bulla
}

\author{
CSH Ng BSc MBBS, ADL Sihoe MB BChir, S Wan MD FRCS PhD, \\ TW Lee MBChB FRCS, AA Arifi MD FRCS, APC Yim MA DM FRCS FACS FCCP \\ Division of Cardiothoracic Surgery, Department of Surgery, \\ The Chinese University of Hong Kong, Prince of Wales Hospital, Sha Tin, NT, Hong Kong
}

CSH Ng, ADL Sihoe, S Wan, TW Lee, AA Arifi, APC Yim. Giant pulmonary bulla. Can Respir J 2001;8(5):369-371.

The present report describes a case of a giant pulmonary bulla in a 32-year-old man that progressed to occupy almost the entire left hemithorax. This report is unique in documenting the natural history of progression of this condition. Bullectomy was performed using the video-assisted thoracoscopic surgery approach.

Key Words: Pneumothorax; Pulmonary bulla; VATS bullectomy; Video-assisted thoracoscopic bullectomy

\section{Bulle pulmonaire géante}

RÉSUMÉ : Le présent rapport décrit le cas d'une bulle pulmonaire géante chez un homme de 32 ans qui a progressé de manière à occuper presque entièrement l'hémithorax gauche. Le présent rapport est exceptionnel en ceci qu'il documente l'histoire naturelle de l'évolution de cette affection. Une bullectomie fut pratiquée en utilisant la chirurgie thoracique vidéo-assistée.

\section{CASE PRESENTATION}

A 32-year-old man, a chronic smoker, presented in June 1999 with increasing cough and shortness of breath, which he had experienced for six days. Chest radiograph showed an $80 \%$ pneumothorax in the left thoracic cavity; this was his second episode of spontaneous pneumothorax (Figure 1). The examination findings were consistent with a pneumothorax. His blood count, biochemistry and alpha $\mathrm{a}_{1}$-antitrypsin level were normal. Computed tomography (CT) showed a large bulla, up to $10 \mathrm{~cm}$ in diameter, in the left apex, with interposing emphysematous parenchyma associated with a pneumothorax. Despite the insertion of two chest drains and suction, the pneumothorax was slow to resolve. A lung function test after re-expansion showed: forced expiratory volume in $1 \mathrm{~s}\left(\mathrm{FEV}_{1}\right) 1.72 \mathrm{~L}$ (45\% predicted); forced vital capacity (FVC) $2.1 \mathrm{~L}$; and $\mathrm{FEV}_{1} / \mathrm{FVC} 82 \%$. He was discharged, and arrangements for an elective video-assisted thoracoscopic (VATS) bullectomy were made.

Unfortunately, the patient refused the operation on numerous occasions. He presented again in July 2000 (one year later) with a three-week history of increasing shortness of breath, decreasing exercise tolerance to one flight of stairs and general malaise. On the chest radiograph (Figure 2) and CT scan (Figure 3), the giant bulla had grown to occupy approximately $90 \%$ of his left hemithorax (approximately $30 \mathrm{~cm}$ ), with only a small volume of ventilated lung in the posteromedial aspect of the left lower zone. A preoperative lung function test showed: $\mathrm{FEV}_{1} 1.43 \mathrm{~L}$ (36\% predicted); FVC $2.1 \mathrm{~L}$; and $\mathrm{FEV}_{1} / \mathrm{FVC} 68 \%$. The patient finally consented to a left VATS bullectomy.

Surgery: A left-sided, three-port technique was used to gain access to the thoracic cavity. The bulla was punctured, and bullectomy was performed with an endoscopic stapling device (EndoGIA30, United States Surgical, Tyco Healthcare, USA). Two chest tubes were inserted, and both lobes re-expanded without air leak.

Pathology: The lung specimen contained two bullae - the larger at the more apical area measuring $32 \mathrm{~cm}$ and the smaller one measuring $3 \mathrm{~cm}$. Microscopically, there were focal atelectatic changes adjacent to the bullae that also con- 


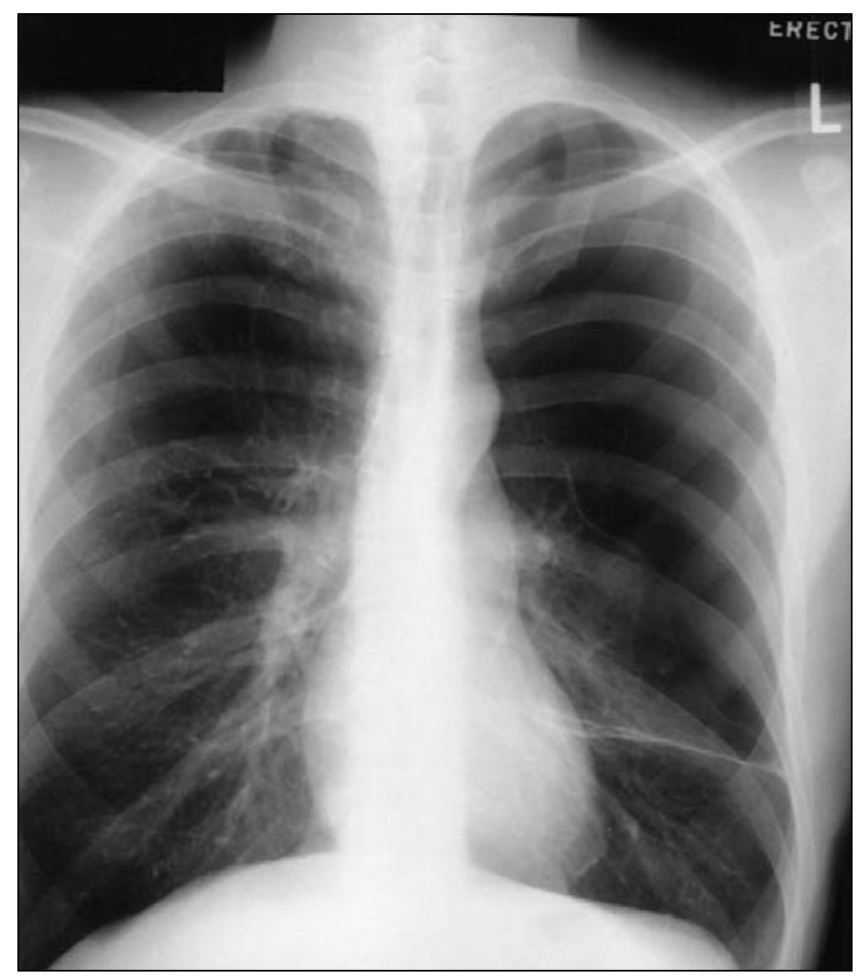

Figure 1) Initial presentation, with $80 \%$ spontaneous pneumothorax

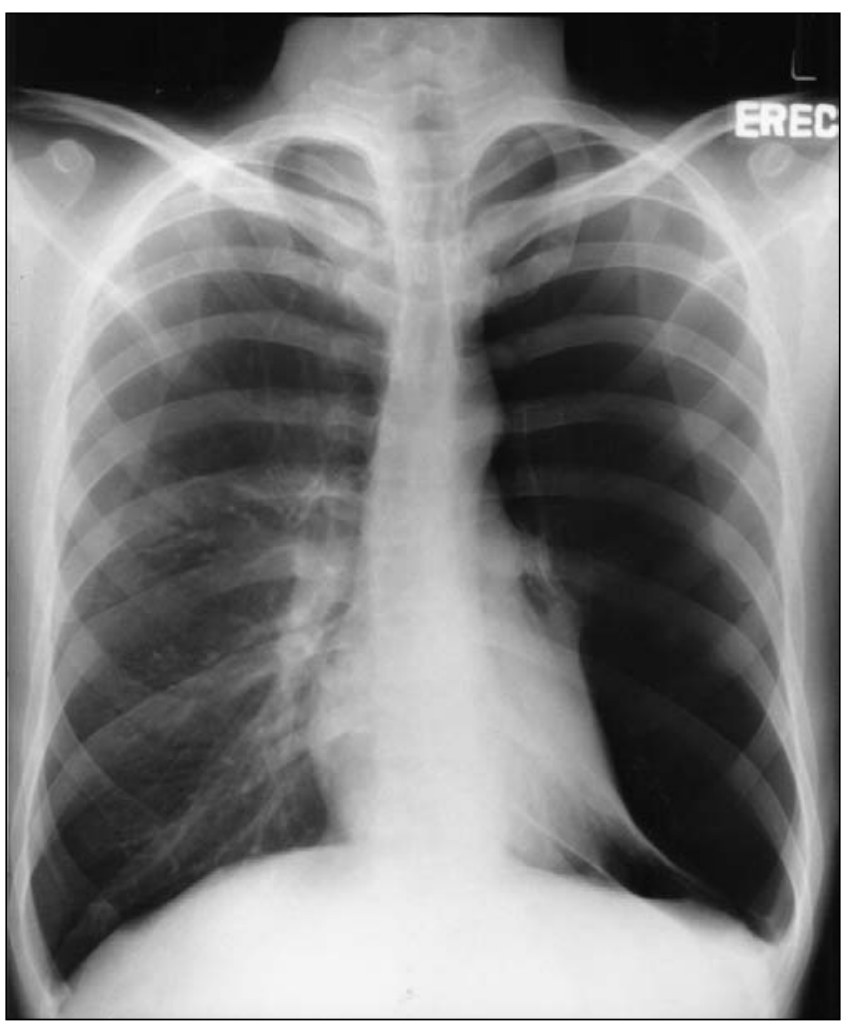

Figure 2) Giant bulla had grown to occupy $90 \%$ of the left hemithorax in one year

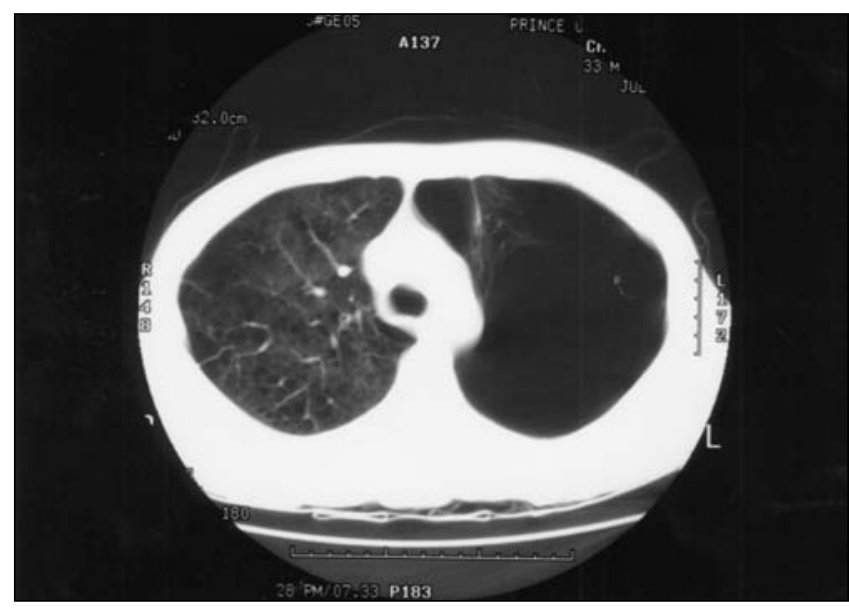

Figure 3) Computed tomography scan showing the large bulla and the remaining small left lower ventilated zone

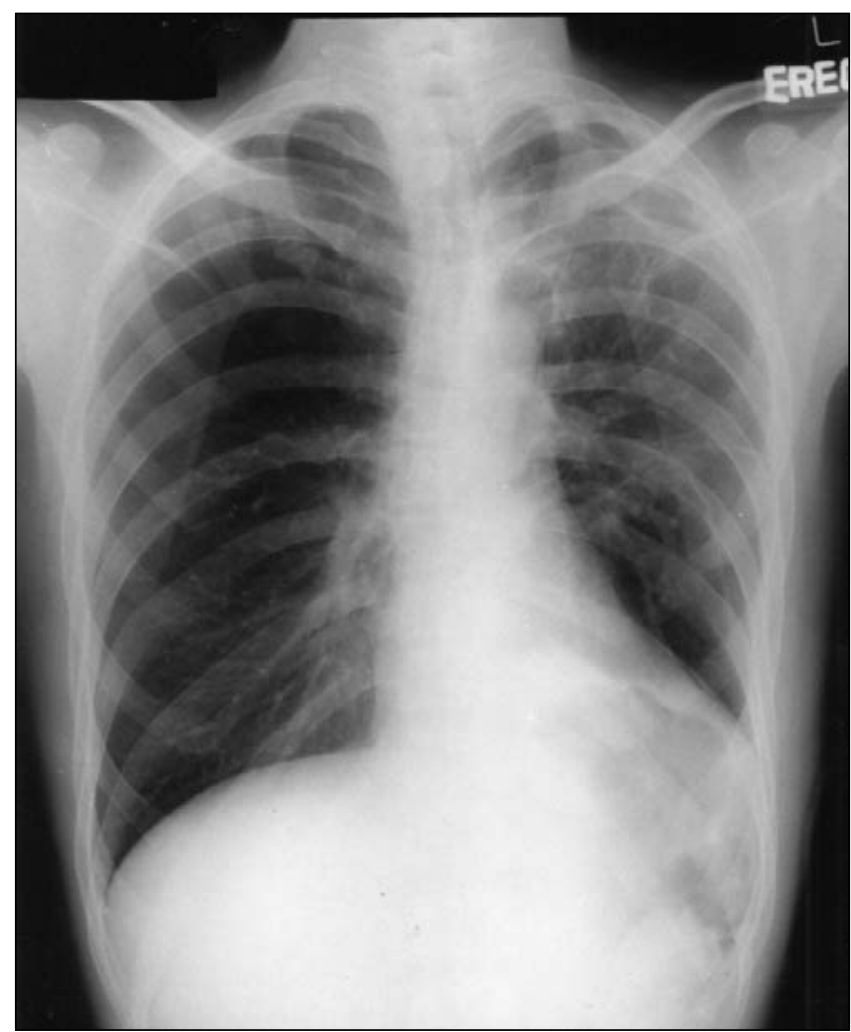

Figure 4) Fully expanded lung at discharge

tained a heavy collection of macrophages with hemosiderin deposits, suggesting old hemorrhages. No granulomas were seen.

Postoperative course: The patient had a persistent air leak postoperatively, and this led to a second VATS exploration, which showed a ruptured bulla in the left lower lobe. The bulla was resected with EndoGIA, and an apical pleurectomy was also performed. The patient made an uneventful 
recovery from the second operation (Figure 4) and was discharged. A lung function test two weeks later showed: $\mathrm{FEV}_{1}$ $2.16 \mathrm{~L}$ (56\% predicted); FVC $3.1 \mathrm{~L}$; and $\mathrm{FEV}_{1} / \mathrm{FVC} 71 \%$. The patient remained well at the last follow-up, six months after surgery.

\section{DISCUSSION}

Idiopathic giant bullous disease, sometimes known as 'vanishing lung syndrome' (1), is a progressive condition characterized by large bullae, which may be seen in association with several forms of emphysema. It is more common in young men, particularly in those who smoke. Bullous disease involves predominantly the upper lobes, with sizes ranging from 1 to $20 \mathrm{~cm}$ (most between 2 and $8 \mathrm{~cm}$ ) (1).

The natural history of these bullae has not been documented in the past, and it is interesting to note how rapidly they can progress. In the present case, the bulla grew rapidly from $10 \mathrm{~cm}$ to $32 \mathrm{~cm}$ over the period of one year. In some instances, the pulmonary bullae can be monitored and conservatively treated. Indications for surgical intervention include the presence of a very large bulla that is: expanding; causing compression of adjacent healthy lung tissue, leading to dyspnea and physical disability; occuring as a manifestation of lung carcinoma; or associated with the development of recurrent pneumothorax or infection. Surgical intervention was the only alternative in our patient, given that he had giant bullous disease-associated pneumothorax, which responded poorly to conventional treatment of tube thoracostomy and suction. Furthermore, the patient had a very large, progressively expanding bulla that was causing compression of the adjacent lung and associated dyspnea.

Over the years, a number of thoracoscopic techniques for bulla treatment have been investigated. These include thoracoscopic bullous endoloop ligation (first described in
1991 using a pretied Roeder knot [2]), thoracoscopic intracavitary bullous drainage (3), thoracoscopic laser bullae ablation (4) and thoracoscopic bullous fibrin glue treatment (5), all of which have been reported with variable success. Bullectomy with endoscopic staples is the most common technique. We did not use pericardial buttress to reinforce the staple resection line (6) during the first operation to minimize cost. The persistent air leak that prompted the second operation was from a ruptured bulla and not from the original suture line. In any event, we performed the additional apical pleurectomy to affect pleural symphysis. Although he initially had some air leak postoperatively, this is not an uncommon occurrence in patients with emphysematous lungs.

\section{CONCLUSIONS}

This case highlights the rapid progression of a giant pulmonary bulla over just one year. VATS bullectomy provides successful treatment for this condition.

\section{REFERENCES}

1. Stern EJ, Webb WR, Weinacker A, Muller NL. Idiopathic giant bullous emphysema (vanishing lung syndrome): imaging findings in nine patients. Am J Roentgenol 1994;162:279-82.

2. Nathanson LK, Shimi SM, Wood RA, et al. Videothoracoscopic ligation of bulla and pleurectomy for spontaneous pneumothorax. Ann Thorac Surg 1991;52:316-9.

3. Urschel JD, Dickout WJ. Thoracoscopic intracavitary drainage for pneumothorax secondary to bullous emphysema. Can J Surg 1993;36:548-50.

4. Brenner M, Kayaleh RA, Milne EN, et al. Thoracoscopic laser ablation of pulmonary bullae. Radiographic selection and treatment response. J Thorac Cardiovasc Surg 1994;107:883-90.

5. Hillerdal G, Gustafsson G, Wegenius G, Englesson S, Hedenstrom H, Hedenstierna G. Large emphysematous bullae. Successful treatment with thoracoscopic technique using fibrin glue in poor-risk patients. Chest 1995;107:1450-3.

6. Yim APC, Ho JKS, Ng SK, Lai CKW, Buckley T. The use of a bovine pericardial buttress in the bilateral staple resection of emphysematous bullae. Hong Kong Med J 1996;2:429-32.

\section{Supported by an unrestricted educational grant from}

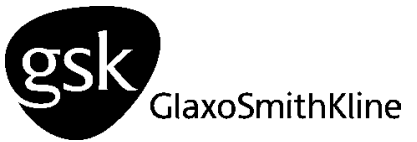




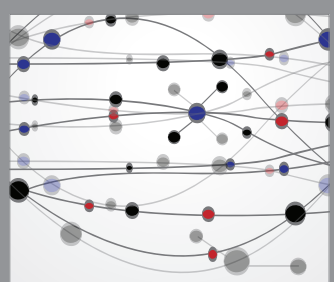

The Scientific World Journal
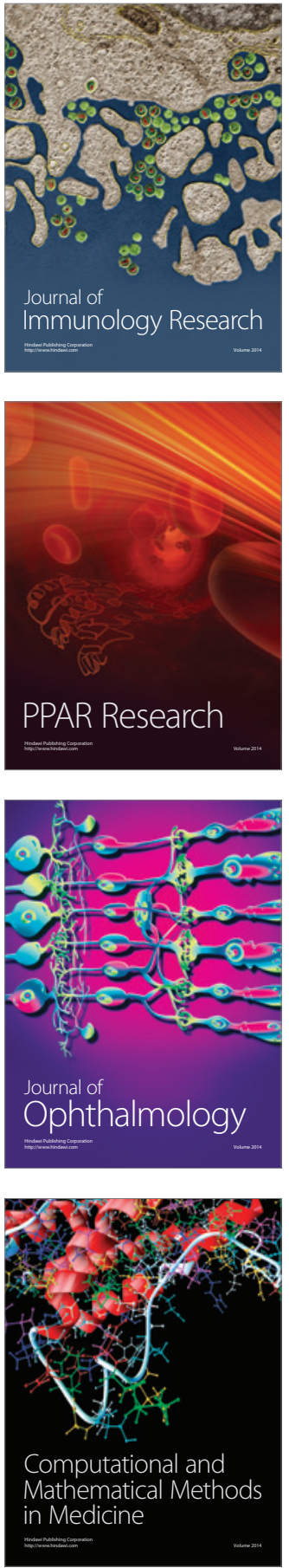

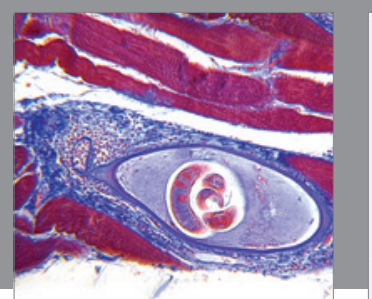

Gastroenterology Research and Practice

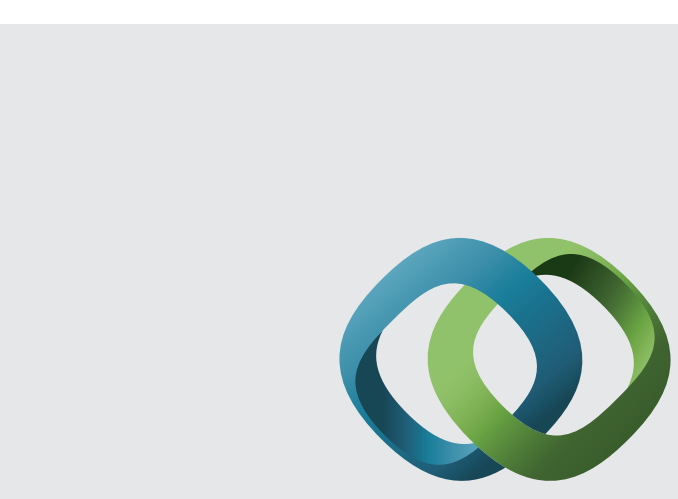

\section{Hindawi}

Submit your manuscripts at

http://www.hindawi.com
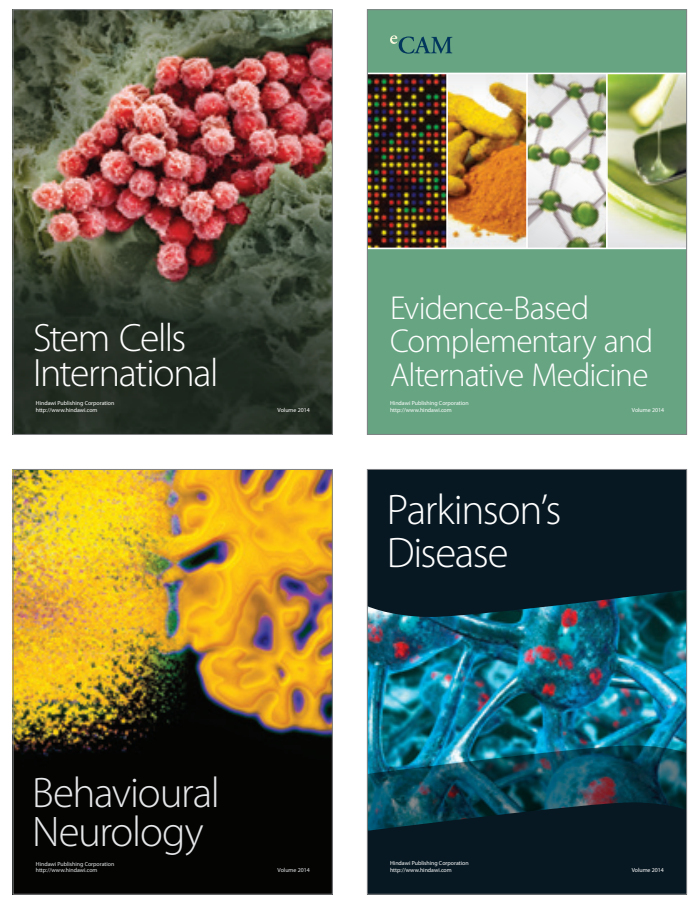
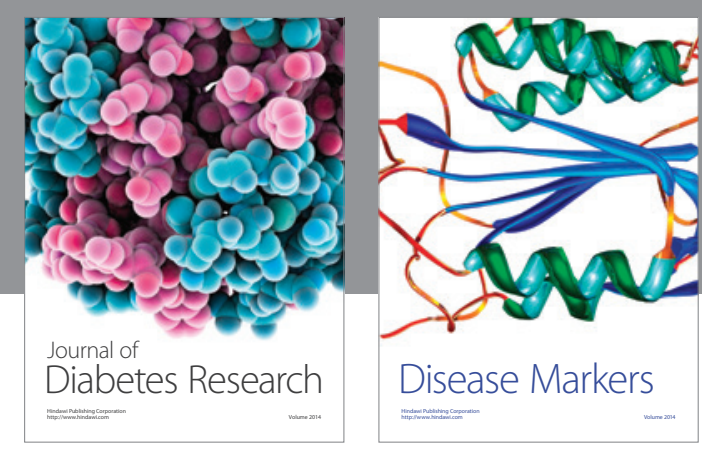

Disease Markers
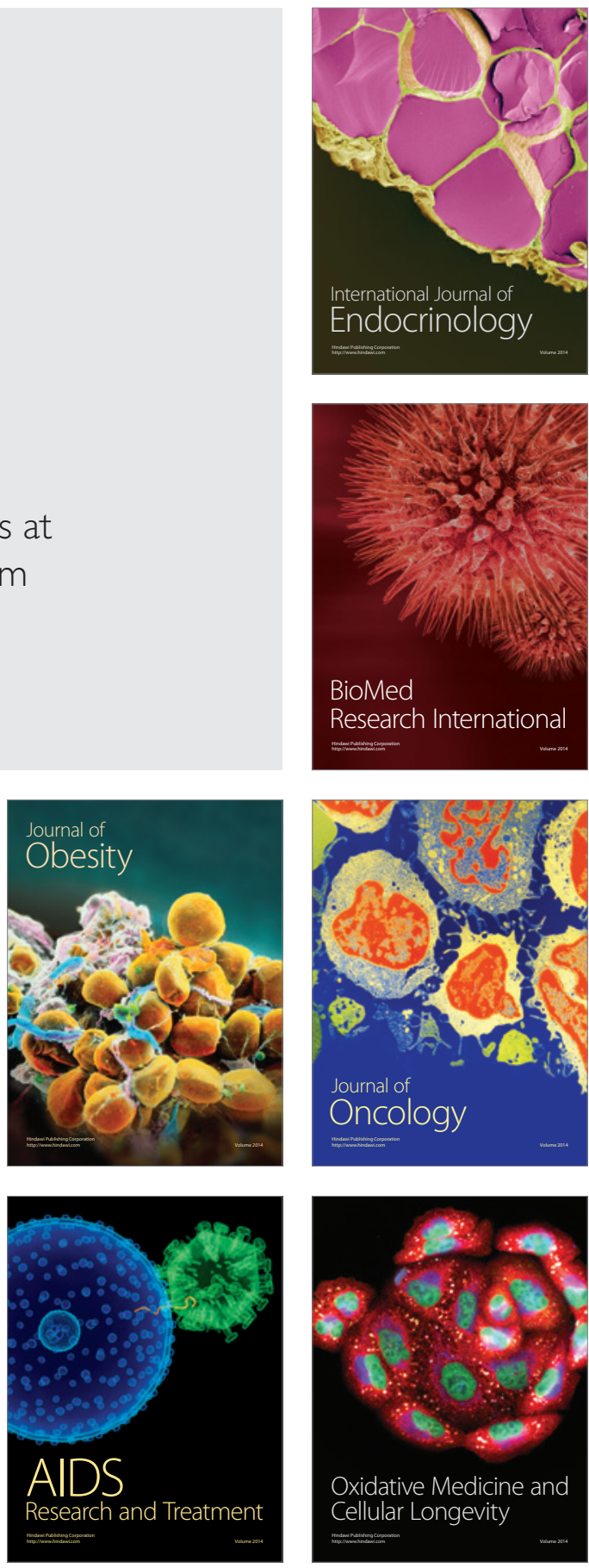